\title{
Laparoscopic Management of Ovarian Dermoid Cyst in a 31-year-old Woman: A Case Report
}

\author{
Cipta Pramana $\odot$
}

\begin{abstract}
Ovarian dermoid cysts, also known as mature teratomas, are one of the ovarian numbers that can develop into malignancy and are mostly found in women aged 20-40 years. Most cases of teratoma mature cystic were discovered accidentally through the imaging examination. We reported a 31-year-old woman with complaints of bleeding from the birth canal for 16 days and accompanied by sharp pain during menstruation. The general condition is good and other vital signs examined were within normal limits. Abdominal ultrasound examination showed a mass in the right adnexa with a size of $12 \times 10 \times 8 \mathrm{~cm}$ and there were longitudinal thin white lines. Laparoscopic right ovarian oophorectomy was performed. After removing the mass was opened and there was a lot of hair in it. There are no complications during surgery and after surgery. The results of the histopathological examination were by the dermoid cyst.

Keywords: Laparoscopy, Ovarian dermoid cyst, Rokitansky nodule.

World Journal of Laparoscopic Surgery (2021): 10.5005/jp-journals-10033-1456
\end{abstract}

\section{INTRODUCTION}

Dermoid cysts, or more commonly known as mature teratomas, are the most common ovarian tumors. About $15-20 \%$ of ovarian tumors are dermoid cysts and occur bilaterally in 10-15\% of cases. The prevalence of developing malignancy is reported in $1-3 \%$ of cases. The highest incidence rate is found in women aged 20-40 years. $^{1,2}$

These tumors originate from totipotent germ cells, which have the ability to become a well-differentiated tissue from the embryonic germ layer. ${ }^{3}$ The cyst may develop from different types of tissues derived from ectoderm, mesoderm, and endoderm, including the hair, bones, teeth, cartilage, nerves, and sebaceous glands. Genetics is a predisposing factor for dermoid cysts, where one study found that the immediate family of patients with dermoid cysts had a higher risk. Common management of dermoid cyst is cystectomy or oophorectomy through surgical laparoscopy. ${ }^{2}$ Therefore, it is important to detect it early so that complications from a dermoid cyst can be prevented.

We reported a 31-years-old woman with ovarian dermoid cysts without complications had undergone laparoscopy oophorectomy.

\section{Case Description}

A 31-year-old woman P1A0 came to the gynecology clinic with complaints of bleeding from the birth canal. The patient complained of having been menstruating for 16 days and was accompanied by sharp pain during menstruation. Blood pressure 110/70 mm Hg, weight $53 \mathrm{~kg}$, and height $152 \mathrm{~cm}$. Other vital signs examined were within normal limits. On laboratory examination, hemoglobin $11.5 \mathrm{gm} / \mathrm{dL}$; hematocrit 33.90\%; platelet count 408/ $\mu \mathrm{L}$; leukocyte count 7.6/ $\mu \mathrm{L}$; and other laboratory tests within normal. Abdominal ultrasound examination revealed a mass in the right adnexa with a size of $12 \times 10 \times 8 \mathrm{~cm}$ and a white longitudinal stripe was seen (Fig. 1).

An exploratory laparoscopy showed a mass in the right adnexa with a size of approximately $13 \times 10 \mathrm{~cm}$ (Fig. 2) and the left adnexa with a normal tube and ovary. It was decided to do a right ovarian
Department of Obstetrics and Gynecology, KRMT Wongsonegoro General Hospital, Semarang, Indonesia/Faculty of Medicine, Tarumanagara University, Jakarta, Indonesia

Corresponding Author: Cipta Pramana, Department of Obstetrics and Gynecology, KRMT Wongsonegoro General Hospital, Semarang, Indonesia/Faculty of Medicine, Tarumanagara University, Jakarta, Indonesia, Phone: +6281326118651, e-mail: pramanacipta@yahoo.com How to cite this article: Pramana C. Laparoscopic Management of Ovarian Dermoid Cyst in a 31-year-old Woman: A Case Report. World J Lap Surg 2021;14(2):138-140.

Source of support: Nil

Conflict of interest: None

oophorectomy. The mass is reduced by aspiration of fluid and a yellowish liquid came out. Then the mass is wrapped in a plastic bag, tied (Fig. 3), and expelled through the bottom of the umbilicus

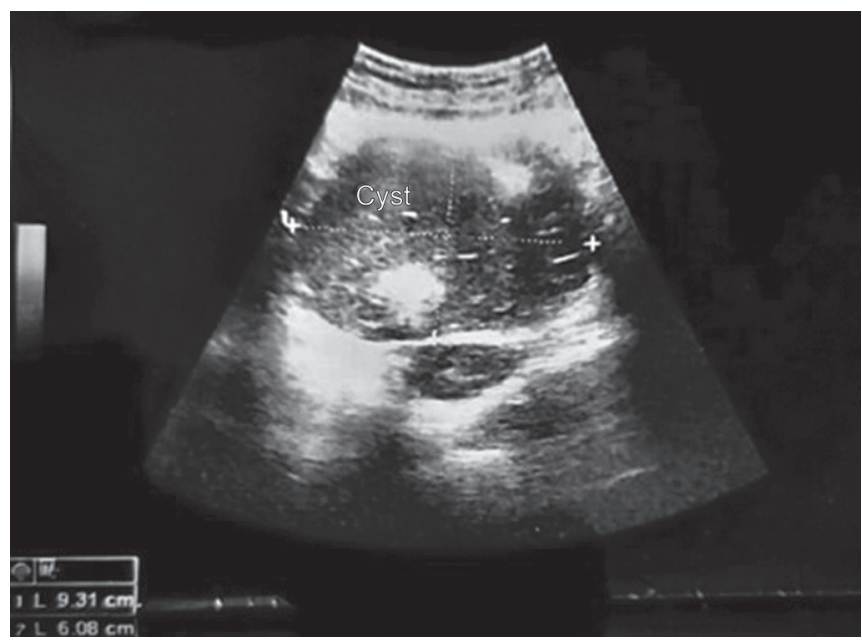

Fig. 1: Ultrasound image of dermoid ovarian cysts

(c) Jaypee Brothers Medical Publishers. 2021 Open Access This article is distributed under the terms of the Creative Commons Attribution 4.0 International License (https://creativecommons.org/licenses/by-nc/4.0/), which permits unrestricted use, distribution, and non-commercial reproduction in any medium, provided you give appropriate credit to the original author(s) and the source, provide a link to the Creative Commons license, and indicate if changes were made. The Creative Commons Public Domain Dedication waiver (http://creativecommons.org/publicdomain/zero/1.0/) applies to the data made available in this article, unless otherwise stated. 


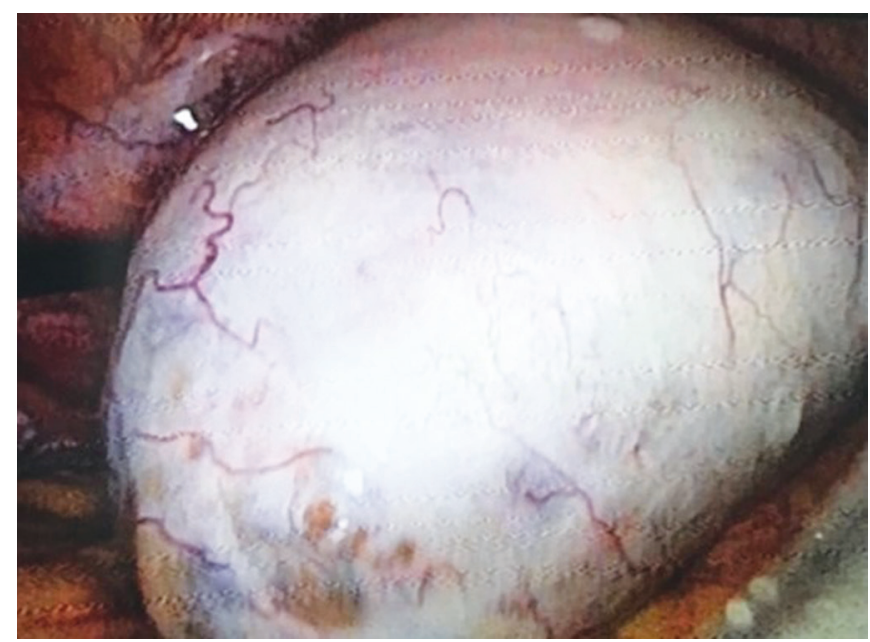

Fig. 2: Dermoid ovarian cyst overview during laparoscopy

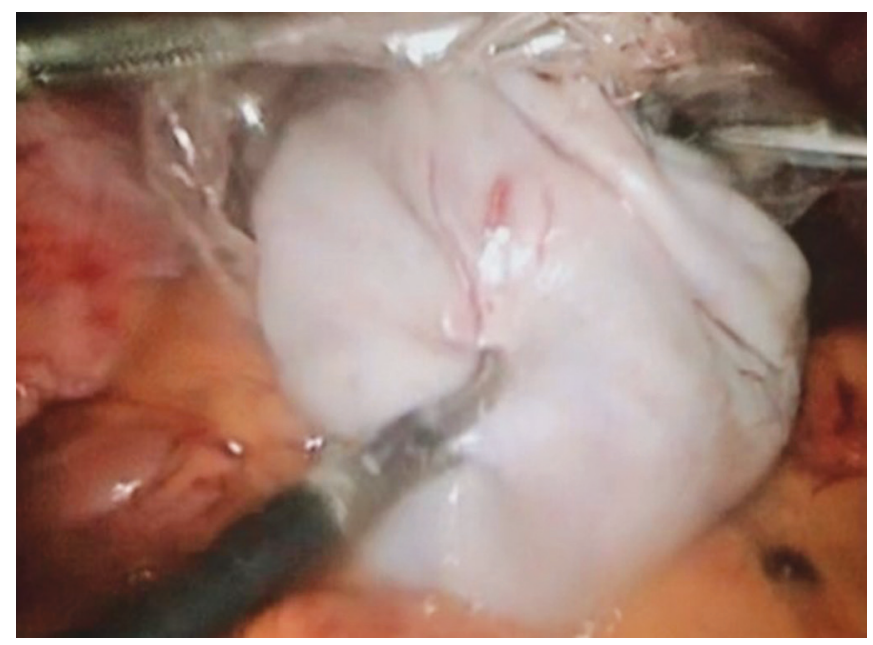

Fig. 3: Dermoid cyst inserted into a plastic bag

(Fig. 4). After removing the mass was opened and there was a lot of hair in it (Fig. 5). Ovarian tumors tissue was sent for anatomical pathology examination.

Histopathological examination results: microscopically showed pieces of ovarian tissue lined with stratified squamous epithelium accompanied by keratin with a stroma composed of fibrocollagenous connective tissue including sebaceous glands, hair follicles and several glandular structures lined with simple cuboidal epithelium, no signs of malignancy were seen.

\section{Discussion}

Benign mature teratoma is the most common benign tumor at a young age. Most cases of mature cystic teratomas are found incidentally on imaging studies. The most common symptom is lower abdominal pain, which is related to the size of the mass. ${ }^{4}$ Because of the association between symptoms and mass effects and doubts about ovarian malignancy, it is necessary to perform resection, usually oophorectomy. ${ }^{5}$

Most mature cystic teratomas can be diagnosed by ultrasound because they have a very characteristic appearance. The following

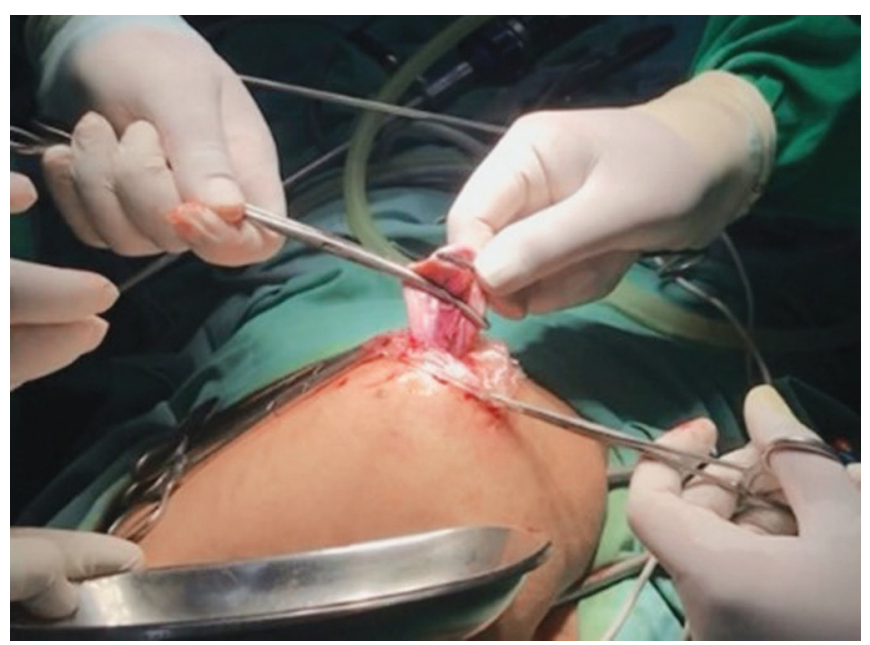

Fig. 4: Dermoid cyst excreted under the umbilicus

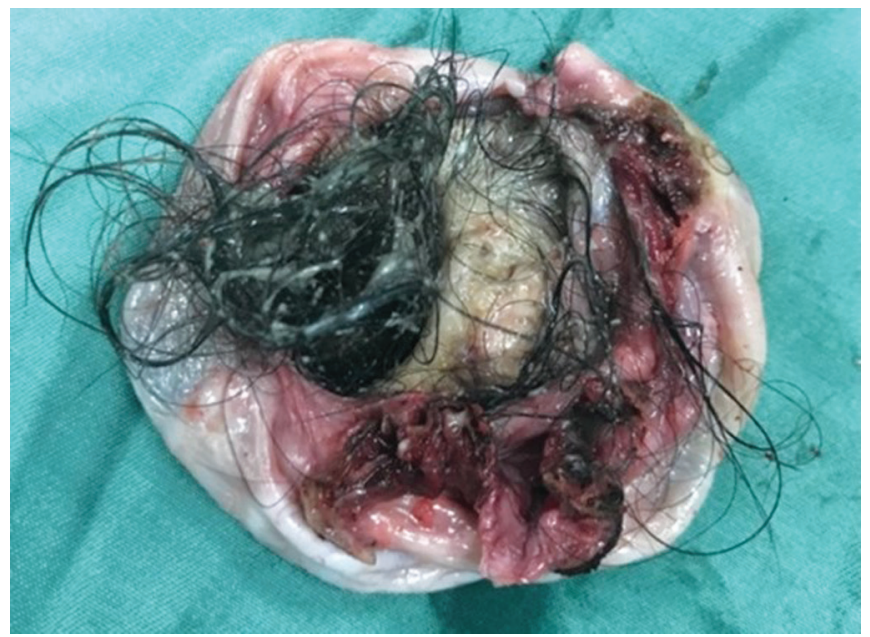

Fig. 5: Dermoid cyst, showing hairs

characteristic appearances can be seen on ultrasonography: the unilocular mass of the cystic adnexitis, Rokitansky nodule, or dermoid obstruction; dermoid mesh which showed echogenic band; and the tip of the iceberg can be seen when fat, hair, and shapeless echogenic tissues are in focus in the foreground causing acoustic shadows on the structures behind them and you can also see linear demarcation. Hair is often a component of teratomas and often mixes with sebum and forms a line in the longitudinal plane and points in the transverse plane. ${ }^{3,6,7}$ Diagnosis was definitively established at the surgical excision. ${ }^{5}$

Some researchers recommend conservative therapy by laparoscopy to maintain ovarian function in young patients with dermoid cysts. ${ }^{5}$ However, there is a general opinion among gynecological surgeons that the rate of leakage of cysts during laparoscopy is higher than that of the laparotomy and that leakage of cyst contents during laparoscopy can potentially cause peritonitis. But it remains questionable whether leakage during laparoscopy can affect the prognosis of the disease. From a literature review with a total of 14 studies documenting 470 cases of laparoscopic dermoid cystectomy, there was leakage of dermoid 
cysts in 310 cases, but significant postoperative complications due to leakage of dermoid cysts were seen in only one case, with chronic granulomatous peritonitis occurring 9 months postoperatively. However, the study did not explain the preventive techniques used to avoid leakage or the action of cleaning fluid from leaking cysts. Irrigation using a jet-wash technique with an excessive amount of fluid to clean microscopic particles from the contents of the cyst is the gold standard for avoiding postoperative complications. From the research of Osama et al., it is said that laparoscopy allows better cleaning and flushing than laparotomy because it is difficult to re-aspire all irrigation fluids in laparotomy. ${ }^{2}$

The advantages of laparoscopy in ovarian cyst management include less postoperative pain, shorter hospitalization and recovery times, and better cosmetic consequences over laparotomy. Several criteria for laparoscopy in the management of ovarian cysts, namely the patient's age (premenopausal), mass size $(\leq 5 \mathrm{~cm})$, mass characteristics on ultrasound, and normal range of tumor markers. Research from Briones-Landa et al. demonstrated that laparoscopy did not increase complications compared to open surgery for benign ovarian cystectomy. ${ }^{5}$

\section{Conclusion}

Dermoid cysts, also known as mature cystic teratomas, are a type of benign tumor of the germ cell ovary. They contain welldifferentiated tissues that are normally found in other organs including teeth, hair, skin, fat, muscle, and bones. It has been reported that patients with dermoid ovarian cysts and successful laparoscopic right oophorectomy had no complications during surgery or after surgery. The patient comes home in good health.

\section{ACKNOWLedgments}

I would like to thank the patients whom I reviewed in this report.

\section{OrCID}

Cipta Pramana @ https://orcid.org/0000-0001-8991-0147

\section{References}

1. Deguchy $Q$, Fananapazir G, Corwin $M$, et al. Benign rapidly growing ovarian dermoid cysts: a case series. J Diagnostic Med Sonogr 2017;33(1):71-74. DOI: 10.1177/8756479316664313.

2. Shawki O, Soliman I, Bahnassy A. Laparoscopic management of ovarian dermoid cysts. Middle East Fertil Soc J 2004;9(1):58-65. https://doi.org/10.3751/194034604783997132.

3. Multani J, Kives S. Dermoid cysts in adolescents. Curr Opin Obstet Gynecol 2015;27(5):315-319. DOI: 10.1097/GCO.000000000 0000206.

4. Nagamuthu EA, Mudavath $\mathrm{P}$, Kishore $\mathrm{N}$, et al. Original research article on cystic ovarian lesions diagnosed as teratomas - a 2-year study in a tertiary care hospital. Int J Res Med Sci 2016;4(9):4136-4142. DOI: 10.18203/2320-6012.ijrms20162949.

5. Uyanikoglu $H$, Dusak A. A huge ovarian dermoid cyst: successful laparoscopic total excision. J Clin Diagn Res 2017;11(8):15-17. DOI: 10.7860/JCDR/2017/29262.10436.

6. Bhasin SK, Malik SM, Sharma G, et al. Ovarian dermoid presenting as acute intestinal obstruction: a rare case report and review of literature. Int Surg J 2015;2(2):283-285. https://doi.org/10.5455/23492902.isj20150533.

7. Pradhan $\mathrm{S}$. The value of ultra sonogram in the diagnosis of ovarian dermoid cysts. J Kathmandu Med Coll 2014;3(1):26-31. DOI: 10.3126/ jkmc.v3i1.10920. 